\title{
MANAGING AIR QUALITY AT THE LOCAL LEVEL: A CASE STUDY
}

\author{
M.J. ROSS-JONES \& J.W.S. LONGHURST \\ Air Quality Management Centre, University of the West of England, UK.
}

\begin{abstract}
The UK's Local Air Quality Management (LAQM) process, introduced by the Environment Act 1995, has resulted in the identification of areas of poor air quality. The next challenge for LAQM is to find and implement cost-effective, long term solutions to improve air quality. In order to achieve this, solutions must come from a wide variety of disciplines, both within and outside local authority (LA) control. This presents a significant managerial challenge to LAs. This study uses a case study methodology to perform an in-depth exploration of the managerial approach for LAQM implemented at an LA within the UK. Evidence of extensive and highly beneficial regional joint working for LAQM is presented. However, a range of ineffective approaches to joint working within the LA are identified, along with a lack of interest and involvement from the local community, senior officers and politicians, which suggests that the implemented approach is unlikely to prove efficient or effective in the medium to long term. The outcomes of this study show a level of consistency with previous studies, implying that similar difficulties could exist in LAQM practice across the UK. This paper provides a model to visualise the implemented managerial approach at the case study LA, and offers models for an improved managerial approach for LAQM. This is designed to address the limitations of the approach implemented by the case study LA.

Keywords: air quality action plans, case study, joint working, local air quality management, local authorities, process effectiveness, process efficiency.
\end{abstract}

\section{INTRODUCTION}

The democratic framework of the UK gives rise to various levels of governance, from central government and government departments and agencies, down to local government. In recent years, the role of local government within this framework has become increasingly vital, due to changes in policy to achieve greater devolution of power. This placed greater emphasis on local government for delivering quality of life in the UK, with the aim of shifting power from central government to local people and those that serve them $[1,2]$.

Local government in the UK comprises 468 local authorities (LAs) [3]. Each consists of a council and executive committee, which provide strategic leadership and decision-making, to direct and oversee the work of various departments and services that form the main service providers. The Local Government Act 2002 [4] refocused the role of LAs beyond the traditional role of service provision, to encompass a number of far-reaching functions aimed at promoting the economic, social and environmental well-being of their communities [5]. These goals were to be achieved through effective partnership working at a local level, both within the structure of LAs and with the appropriate public and private agencies that also serve to provide for the needs of local communities $[5,6]$.

The functions of LAs, and the structure through which these are performed, have been determined by Acts of Parliament [5]. The Environment Act 1995 [7] is one such act that gave all LAs within the UK the powers and responsibility to adopt the control of air quality as a mandatory function.

The Environment Act 1995 [7] required the production of the National Air Quality Strategy [8], which was revised in 2000 [9] and again in 2007 [10]. It set out a new approach to manage air quality in the UK called the Local Air Quality Management (LAQM) process. This process took a step away from the emissions based control of old, towards a new human health effects-based approach $[11,12]$. Following the introduction of the European Ambient Air Quality Framework Directive [13], the LAQM process also has a key role to play in ensuring the UK, as a member state, complies 
with EU legislation [10]. While the government took ultimate responsibility for meeting the specific health-related air quality targets of both the European and national frameworks of air quality management, a large emphasis was placed on action at a local level $[9,14]$.

LAs were handed responsibility for identifying and remediating areas of poor air quality by implementing local solutions, tailored to local circumstances [15]. The first part of the LAQM process required all LAs in the UK to conduct a review and assessment (R\&A) of air quality in their area of jurisdiction, and designate an Air Quality Management Area (AQMA) where it appears likely that air quality targets will not be achieved [7]. This constitutes the 'technical' aspects of LAQM. Where AQMAs are designated, LAs must develop and implement an Air Quality Action Plan (AQAP) outlining measures to be introduced to work towards the statutory targets [16]. This was based on a belief that these areas of poor air quality would be best dealt with using local measures implemented through the LAQM process [17]. This approach, requiring the LA to coordinate its actions internally, and probably externally, and to align existing policy processes and strategies to address the identified problems, constitutes the 'managerial' aspects of LAQM.

LAQM presents a significant challenge to LAs. Technical capabilities are required in order to produce detailed modelling and monitoring to effectively identify areas of poor air quality [18]. Managerial capabilities are required to ensure a collaborative and coordinated approach, in which solutions to identified air quality problems are integrated into a range of policy measures throughout the LA $[18,19]$. In order to be effective these policy measures need the support and involvement of a number of external stakeholders, such as the local community, neighbouring authorities and external agencies $[14,17]$. LAs expressed concern over these challenges and their capability to undertake these LAQM responsibilities effectively. This resulted in national resources, such as specific guidance documents, emissions inventories, and telephone and email help desks, being provided by the government to aid LAs [14, 15, 20]. A number of these resources [17, 21-23] relate to managerial aspects of LAQM, and provide guidelines for best practice managerial approaches.

Throughout implementation of LAQM, it has become increasingly clear that managerial aspects may well be crucial in determining its success $[17,24]$. Despite this, existing studies of UK practice in LAQM have identified that authorities have far greater capability for technical aspects of the process. Since the implementation of the LAQM process, the technical capabilities of LAs have flourished to an extent where they are believed to be sufficient to effectively identify areas of poor air quality $[14,15]$. A strongly defined Quality Assurance/Quality Control mechanism has also been developed to oversee technical practice and appraise R\&A reports.

The mechanism to oversee managerial practice and appraise AQAP development and implementation has not been strongly defined, and studies of UK practice highlight a serious lack of managerial capabilities $[14,15]$. This reflects the focus of LAQM thus far, which has been largely placed upon technical aspects of the process. A significant change in focus, towards managerial aspects, is now required if the LAQM process is to prove effective at remediating the areas of poor air quality identified by LAs and their improved technical capabilities.

Studies of current UK practice for LAQM have drawn heavily upon findings from questionnaire surveys $[16,19,25]$. This has provided valuable evidence of the development of LAQM practice, and has identified various deficiencies in the managerial approaches being implemented. However, evidence that has gone beyond describing existing managerial approaches and their apparent deficiencies, to evaluate their efficiency and effectiveness in situ, has thus far been limited. This study was designed to provide such evidence.

This study examined the managerial approach for LAQM at a case study LA operating within the UK's LAQM framework. The case study LA lies on the outskirts of a major conurbation and has a population of approximately 250,000 . It has a strong association with neighbouring authorities through a regional body, and was included in a regional AQAP, following declaration of part of its 
borough as an AQMA. This was declared for the predominantly traffic-related pollutants nitrogen dioxide $\left(\mathrm{NO}_{2}\right)$ and particulate matter $\left(\mathrm{PM}_{10}\right)$. This paper describes the implemented managerial approach found at the LA and uses a novel, qualitative approach to evaluate its efficiency and effectiveness. It provides a number of recommendations for improved managerial practice. The study offers a contribution to the field of LAQM research by presenting an in-depth, case study of managerial practice within a single LA, in a form that has not been previously reported.

\section{EVALUATING THE EFFICIENCY AND EFFECTIVENESS OF THE MANAGERIAL APPROACH FOR LAQM IMPLEMENTED AT THE CASE STUDY LA}

Although efficiency and effectiveness are clearly defined performance domains, there is no consensus view as to which criteria to use in the measurement of these domains [26-28]. This has been reflected in LAQM, which has yet to provide definitive criteria to evaluate the efficiency and effectiveness of implemented managerial approaches. Due to the relative infancy of the LA's managerial approach, coupled with the potential influence of other factors (such as European and national actions) on ambient air quality concentrations, it was not feasible to use a quantitative approach utilising air quality trend data. A novel, qualitative approach was therefore developed for this study, based on established definitions of these two performance domains.

Efficiency has been defined as an input-output ratio or comparison, whereas effectiveness refers to an absolute level of either input acquisition or output attainment [29]. In order to equate these definitions to the LAQM process, this paper provides a definition of the input and output of LAQM. The LAQM process was implemented to provide the output of air quality that poses no significant risk to health or quality of life [9]. The various inputs required to conduct LAQM can be summarised as resources (i.e. technical equipment, and professional and financial capacity). This paper uses these criteria to provide an informed, subjective evaluation of the efficiency and effectiveness of the managerial approach for LAQM implemented at the case study LA.

\section{METHODOLOGY}

The case study LA was selected using criterion-based sampling, in which criteria are developed to ensure the most appropriate and relevant cases are selected for study [30]. The case study LA met the criteria defined as it had an active LAQM managerial approach, and, in addition, was conveniently located for the researcher. The LA agreed to partake in the study and appropriate permission was obtained. Prior to this, procedures for anonymity, confidentiality and participant withdrawal were designed to ensure ethical integrity and minimise any risks of participation in the study. Procedures were approved by the Ethics Committee of the Faculty of Applied Sciences, University of the West of England, prior to commencing the study.

Semi-structured interviews were carried out with a number of consenting stakeholders, and this formed the primary method of data collection for the study. This method was selected as it provides direction to the interviews, ensuring that the content focuses on the crucial issues of the study, without imposing too much structure in obtaining responses and allowing for exploration of unexpected and potentially significant responses [30, 31]. Selection criteria were defined for interview participants and aimed to identify key stakeholders in the managerial approach for LAQM implemented at the LA, including the regional aspects. Participants included environmental health, land use planning, transport planning and transport engineering professionals, and an officer working for a regional public transport authority. In addition to this data collection method, document analysis [32, 33] was undertaken where relevant documents were available. This served to enhance the validity of the findings by providing aspects of both data source and methodological triangulation [30, 34, 35].

A semi-structured interview guide was designed. Open-ended questions, developed to avoid ambiguity, bias and dichotomy, were grouped into sections covering key elements of the managerial 
aspects of LAQM. Sections included information dissemination, engagement of stakeholders, decision-making and policy implementation, training, capacity and capability in LAQM, and potential improvements to the implemented approach. These sections contained questions intended to identify the implemented approach, qualitatively evaluate its efficiency and effectiveness and elicit suggestions for improvements. Questions to ascertain the main constraints to achieving an effective approach, and how these could be overcome, were also included. An opening and closing statement, and a number of introductory questions were included in the guide to provide context to the interview and ensure that ethical integrity was maintained.

The interview guide was piloted with an environmental health professional from the case study LA, who had a broad knowledge of the LA's managerial approach for LAQM. This allowed the guide to be tested for clarity, and its ability to facilitate responses relating to the research questions. A number of minor structural changes were subsequently made to the guide to improve the clarity and flow of questions. Interviews were audio-recorded, where permitted by the participant, and contemporaneous notes were taken. Summary transcripts for each interview were produced from these records, focusing around the main study points and any key phrases. To ensure ethical integrity and enhance reliability and validity, transcripts were sent to each participant to check interpretations, add additional comments and confirm consent.

Data analysis was conducted on interview transcripts and relevant documents based upon a sixphase thematic analysis approach set out by Braun and Clarke [36]. A summary of this data analysis approach, as undertaken in this study, is provided in Table 1. Themes identified using this approach form the evidence base from which this paper will draw its conclusions.

Table 1: Summary of the six-phase thematic analysis process undertaken.

\begin{tabular}{|c|c|}
\hline Phase & Description of the process \\
\hline $\begin{array}{l}\text { 1. Familiarise with } \\
\text { the data }\end{array}$ & $\begin{array}{l}\text { Raw data transcribed, transcripts read and re-read, notes made recording } \\
\text { initial ideas, any data irrelevant to research questions was removed to } \\
\text { produce final transcripts for analysis }\end{array}$ \\
\hline $\begin{array}{l}\text { 2. Generate initial } \\
\text { codes }\end{array}$ & $\begin{array}{l}\text { Final transcripts read and all segments of data were systematically coded } \\
\text { for features. Segments were coded for as many features as necessary. } \\
\text { Once all data was coded, data were collated by code }\end{array}$ \\
\hline 3. Search for themes & $\begin{array}{l}\text { A list of codes was produced and related codes were gathered into potential } \\
\text { themes. All data relevant to each theme was then collated }\end{array}$ \\
\hline 4. Review themes & $\begin{array}{l}\text { Data relating to each potential theme was read, and considered in relation } \\
\text { to other themes. Themes were scrapped if insignificant or had insufficient } \\
\text { or ambiguous supporting data, and were merged with other themes where } \\
\text { appropriate. Thematic maps were produced to visualise theme levels (main } \\
\text { themes, sub-themes, isolated themes) and relationships between themes. } \\
\text { The validity of themes was considered in relation to entire data set }\end{array}$ \\
\hline $\begin{array}{l}\text { 5. Define and name } \\
\text { themes }\end{array}$ & $\begin{array}{l}\text { A detailed analysis was conducted on each theme by organising data into a } \\
\text { coherent account, with narrative. This defined each theme, identified any } \\
\text { related main or sub-themes, and its relevance to the study and its research } \\
\text { questions. Names were given to each theme for the written account }\end{array}$ \\
\hline 6. Produce the report & $\begin{array}{l}\text { The final analysis of themes was conducted and presented in the report. Themes } \\
\text { presented concisely, coherently and logically to provide an interesting and } \\
\text { non-repetitive account of the data collected, for discussion in relation to the } \\
\text { research questions and literature }\end{array}$ \\
\hline
\end{tabular}

Source: Adapted from Ref. 36. 


\section{COMPARING THE PROCESS WITH PRACTICE: IMPLEMENTATION OF THE ADVISED MANAGERIAL APPROACH FOR LAQM PROVIDED \\ IN GUIDANCE AT THE CASE STUDY LA}

Government guidance [17] is the primary tool through which advice was provided to LAs on the implementation of effective managerial approaches for LAQM. Evidence regarding the implementation of this advice at the case study LA is provided from 12 stakeholder interviews and relevant available documents. A model presenting an overview of the implemented approach is shown in Fig. 1. It shows an approach that is coordinated by environmental health, includes a variety of stakeholders and a strong regional approach for conducting LAQM work, with links to the region's Local Transport Plan (LTP). The importance of the regional approach is evident in the inclusion of the case study LA in a regional AQAP. The AQAP outlined measures to be implemented across the region to improve air quality, but also contained a more detailed annex for each LA within the region. These annexes provided a local focus to the implementation of air quality policy.

\subsection{Intra-authority joint working for LAQM}

Evidence from interviews and document analysis indicated that there was no defined mechanism or coordination within the LA to facilitate joint working. Information dissemination between departments had previously been limited to the infrequent attendance of an environmental health professional at transport meetings to present air quality information, and the dissemination of air

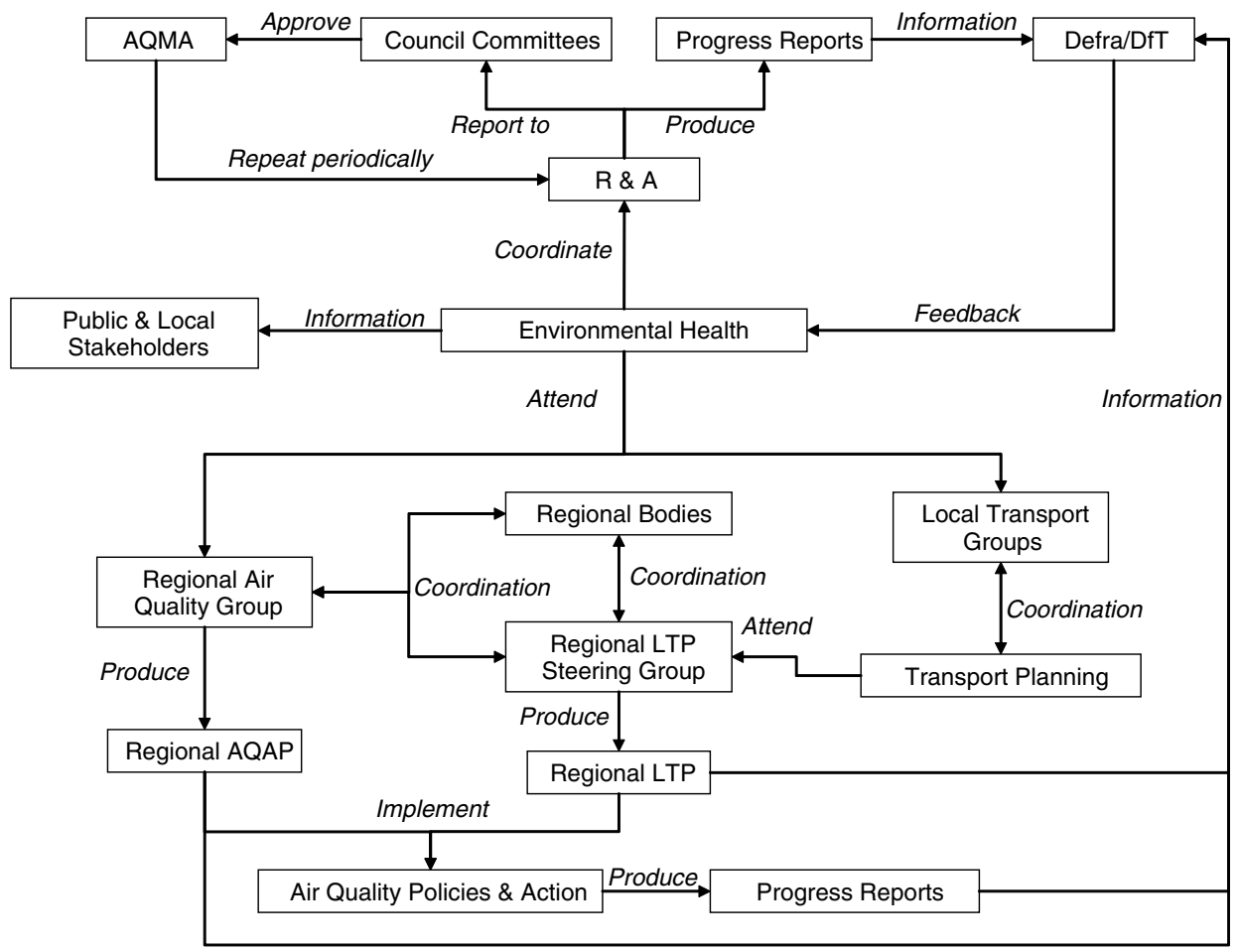

Figure 1: Overview of the managerial approach for LAQM implemented at the case study LA. 
quality reports to transport departments. Evidence suggested that no other departments received air quality information on a regular basis. In evaluation, where information dissemination was occurring, it was felt that neither the methods, nor the information currently being disseminated were effectively informing recipient officers.

Further concern related to methods employed to produce the LA's annex of the regional AQAP. Whilst it contained policies that fell under the control of a range of departments, evidence strongly suggested that there was no coordination of the responsible officers to develop and implement this plan to improve air quality. Instead, the plan was developed through environmental health requesting information from relevant departments on existing, or nascent policy measures, which could have a beneficial effect on air quality. These policy measures formed the majority of the plan.

\subsection{Senior council officer and politician involvement}

This study failed to identify a senior council officer or politician within the LA who could be described as an active and engaged stakeholder in its managerial approach for LAQM. Evidence gathered suggested that the only previous involvement of this stakeholder group has been through attendance at council and regional committees, where decisions are made regarding policies that may have significant impacts on air quality. Evidence of council committee decisions specifically related to air quality was limited to those regarding declaration of the AQMA. Conversely, regional committees, involving senior council officers and politicians from all LAs within the region, have been more engaged in the managerial aspects of LAQM, for example, through taking a role in approving the regional AQAP reports.

\subsection{Regional joint working for LAQM}

The case study LA works in close partnership with its neighbouring authorities through a regional association. This association is organised to incorporate an environmental protection division, part of which focuses on air quality. Through these bodies, LAs within the region have developed a strong approach for coordinating regional LAQM. The approach involves an extensive network of steering groups, working groups, manager groups and senior committees, which involve a wide range of stakeholders across the region. Stakeholders include environmental health, transport planning, passenger transport authorities, the highways agency, senior council officers and politicians.

The various groups within this regional network produce both air quality and transport policies, which direct air quality policy implementation at a local level. Environmental health and transport professionals provided predominantly positive evidence regarding both the efficiency and effectiveness of this regional approach, especially with regard to the Regional Air Quality Group (RAQG), which primarily comprises the environmental health professionals responsible for LAQM at each LA within the region.

A significant proportion of interview participants had an active involvement in the RAQG. Participants felt the group brought efficiency to LAQM work through sharing knowledge, expertise and resources, and removing elements of repetition that would occur should authorities carry out the work alone. Effectiveness was also provided due to the consistency brought to LAQM work across the region, and an increased capacity and capability for the work.

It was also apparent that the regional association has facilitated a more effective integration of air quality and transport policy through the regional LTP process. The association provides a structure into which transport and air quality officers can manage their relationships, communicate effectively and integrate their work. Links to the RAQG have been established by the Regional LTP Steering 
Group (RLTPSG), which develops and oversees implementation of the LTP. These links were facilitated via the attendance of a transport professional with primary responsibility for air quality at the RLTPSG. This individual also represents RLTPSG at RAQG meetings and coordinates a Regional LTP Air Quality Working Group (RLTPAQWG). The RLTPAQWG is attended by individuals from both groups, and serves to carry out certain air quality tasks for the RLTPSG.

An example of a task given to the RLTPAQWG was the organisation of a workshop that focused on actions to improve air quality. This was attended by a range of stakeholders, drawn from both a regional and national audience. It aimed to discuss moving forward with air quality actions by generating ideas, awareness and support from key stakeholder groups, and thus facilitate more effective implementation. Attending stakeholders included transport, planning, sustainability and senior council officers, the highways agency and the environment agency. However, the sole attendees from the case study LA were environmental health professionals.

Despite a general optimism regarding the integration and increasing consideration of air quality in transport policy, there were suggestions indicating that it is still not proving wholly effective. This stemmed from the fact that the integration and consideration of air quality was limited to the regional level, and has not extended down to officers working at LA level.

\subsection{Public and local stakeholder involvement}

This study failed to identify an individual within the public or local stakeholder group as actively involved in LAQM at the case study LA. Methods employed by the LA to involve this stakeholder group have mainly comprised of consultation exercises, carried out at various stages of the process, and the provision of information on request and via air quality internet pages. Documentary and interview evidence suggested that the consultation exercises have generated a limited number of responses, which were considered unrepresentative of the borough's population. For these reasons, responses were not given serious consideration in developing air quality policies. Environmental health professionals generally felt that these low response rates illustrate the lack of interest and willingness in this stakeholder group to be involved in improving air quality, which consequently undermines and devalues the process of consultation.

\subsection{Joint working with external agencies}

Again, there was no evidence that a member of this stakeholder group was actively involved in LAQM at the case study LA. The most relevant evidence of this group's involvement was, indirectly, via the highways agency's representation in the RLTPSG. Findings show that effort has been made to involve both the highways agency and the environment agency in the process at the RAQG, but thus far their input has been limited.

\section{PARTICIPANT EVALUATION OF THE IMPLEMENTED MANAGERIAL APPROACH}

\subsection{Main constraints to an effective managerial approach}

Evidence of two main constraints to an effective managerial approach featured strongly in the data set. The first concerns the low priority given to air quality by key stakeholder groups. This includes the public, who participants felt were unwilling to support measures that would require a behaviour change away from car use, which was considered key to improving air quality. This was also linked to a lack of political willingness to implement measures due the potential political ramifications, and the well documented conflict of environmental factors with economic and social factors $[37,38]$. 
It was also identified that air quality was not a priority for key, non-environmental health stakeholders within the LA (primarily transport and land planning professionals). As a consequence, air quality does not receive adequate consideration within the work of these key stakeholders.

The second main constraint identified concerns the inappropriateness of managerial elements of LAQM. Major concerns were voiced regarding the lack of local solutions to the main air quality problem identified across both the region and the UK, namely, road transport [10]. Participants felt that either national implementation of air quality policy to tackle this problem, or provision of more prescriptive guidance on implementing air quality policy, would prove more effective. The appropriateness of the coordinating role played by environmental health in the managerial approach to LAQM was also called into question. Responsibility for LAQM within the case study LA has been given to two senior environmental health professionals, who take on the role in addition to other wide-ranging duties. Whilst this has been sufficient in terms of coordinating the technical aspects of LAQM, environmental health participants interviewed felt that they had neither the capacity, remit nor status to enable them to coordinate the LA's managerial approach effectively.

\subsection{Improvements to the current managerial approach}

A wide range of suggestions were provided that focused on improving the current managerial approach. The most prevalent suggestions across the data set were raising the profile of air quality within all the key stakeholder groups, and relieving the burden placed on environmental health professionals to carry out and coordinate LAQM at the LA.

\section{DISCUSSION}

A number of limitations to the study were imparted by the case study methodology and the circumstances under which it was conducted. The in-depth nature of case studies mean they are inherently labour intensive [39]. Therefore, as the study had time and resource limits, limitations to the potential scope of the study were inevitable. These limitations manifested themselves through limiting both the number and range of participants that could be included in the study, and reducing the potential for applying triangulation techniques to improve reliability and validity.

Despite these limitations, the methodology was designed to overcome their implications through the confidence that could be ascribed to the methods and their outcomes. The methodology recruited a range of key stakeholders, which included the individuals that had been most active and engaged in the managerial approach for LAQM implemented at the LA. Certain key stakeholder groups were not represented. However, a large amount of detailed evidence was collected, from enough individuals who were well placed to provide a sufficiently detailed insight into the strengths and limitations of the LA's managerial approach. A number of methods were used to ensure the ethical integrity, reliability and validity of these findings. Therefore, it is considered that this study applied a robust methodology to provide evidence that could be used to achieve the aims of the study.

Findings presented in this paper provide evidence that the managerial approach for LAQM implemented at a case study LA departs in many aspects from the advised approach provided in government guidance. The regional aspect of the approach is clearly the aspect most comparable to that recommended in guidance, and is also the aspect that has been implemented with the greatest efficiency and effectiveness. Air quality problems are transboundary and as such, require regional collaboration to develop and implement effective solutions [25]. This is reflected in guidance, which attaches great importance to the establishment of regional air quality groups to help deliver aspects of the LAQM process [17]. Evidence of current UK practice indicates that this advice has been heeded by LAs, and regional joint working is thought to be both widespread and adequate [15, 16]. 
The findings of this study are consistent with this evidence and indicate that the extensive regional approach, in which the case study LA has been actively engaged, provides numerous benefits to participating LAs. This has resulted in greater efficiency, as it has required fewer resources to produce a larger number of policies than if the LA was working alone. These policies are also more likely to be effective as they have been developed by a group of officers with a wide range of air quality experience, are consistent across the region and, where appropriate, have been integrated and implemented into the Regional LTP.

It has been firmly established that the involvement and support of a number of key local stakeholders, such as relevant council departments (particularly transport, land use planning, economic development and local agenda 21), senior officers, politicians and the local community, are required for the effective implementation of air quality policy [14, 15, 22, 24, 25]. Evidence of current UK practice has identified that a number of difficulties exist in engaging these stakeholder groups in LAQM [15, 16, 40, 41].

The engagement of these key stakeholders is where the identified approach at the case study LA departs from that which is set out in guidance. Where this departure is most clear is through the evident lack of communication and coordination for LAQM within the LA. Without effective communication and coordination between relevant officers within the LA it is highly likely that officers outside environmental health are ill-informed of air quality issues in the borough and their role in determining and prioritising solutions. The consequence of this can be seen in evidence relating to air quality policies included in the authorities annex of the regional AQAP. Here, it was identified that rather than integrating air quality policy into the policies and work of relevant disciplines, the current method is in fact doing the opposite, and integrating the policies and work of relevant disciplines to produce air quality policy. It is therefore clear that the identified air quality issues in the borough were not driving the development of many of the identified solutions, and thus it is difficult to see how they will be effective.

Evidence also points to difficulties being experienced in gaining the support and involvement of other key stakeholders, most importantly, senior officers, politicians, the local community and external agencies, such as the highways agency. Whether it stems from the low priority of air quality, the inappropriate or under-defined roles of stakeholders or the ineffectiveness of methods employed by the LA, the evidence and analysis presented in this paper provide a clear indication that the current level of involvement of key stakeholders in the managerial aspects of LAQM at the LA is a major factor in preventing it from being effective.

In evaluation of the managerial approach for LAQM implemented at the case study LA, as a whole, it could be argued that the approach provides a certain level of efficiency for carrying out LAQM work. This is achieved by employing methods that minimise required inputs. This can be seen in methods used to consult the public, the manner in which the AQAP is produced and through sharing LAQM work in the RAQG. In some respects, the approach is also effective as it achieves an output, in that it has enabled the LA to meet the statutory requirements of LAQM. These include conducting stakeholder consultation on plans and reports, and the production of an AQAP and progress reports on its implementation. This highlights a potential discrepancy in defining outputs of LAQM.

The government has placed responsibility on LAs to work in pursuit of the air quality objectives, but have yet to place a statutory obligation on LAs to meet these objectives $[7,10]$. In this sense, the LA has implemented an approach that uses a minimal amount of resources to meet its statutory obligations, and could therefore be seen as both efficient and effective. Ultimately however, it is the aim of LAQM to deliver air quality that meets the objectives, and thus managerial approaches should be judged on their ability to produce this output.

The effectiveness brought to the approach by its regional aspects will not, on its own, be sufficient to improve air quality in the borough of the case study LA. It provides regional air quality policy that 
is integrated into regional transport policy where appropriate. However, the lack of effective involvement of key local stakeholders greatly reduces the likelihood of air quality policy being supported and integrated into relevant policies at the LA. Without this support and integration it is highly likely that the approach will not be effective. This will have a major influence on the efficiency of the approach. Despite the development of an efficient approach at the LA for carrying out their current statutory LAQM obligations, a large amount of resources have been used in conducting this work. Without an effective managerial approach to deliver the desired outputs, these resource inputs far exceed the desired outputs, creating an approach that is ultimately inefficient.

This study provides a detailed evaluation, some 10 years into the application of LAQM in the UK, and demonstrates technical competency and managerial weakness at this stage of the process' development. The value in this evaluation is in enabling the identification of weaknesses in the way in which the process has been implemented. In order to aid the further development of effective managerial approaches for LAQM, a number of recommendations for improved practice were identified in this study, which may provide solutions to the various difficulties found.

A conceptual model that visualises an improved managerial approach at the case study LA is shown in Fig. 2. This includes appropriate links to the regional approach, which despite being the most efficient and effective aspect of the overall approach also has opportunities for improvement. Therefore, a second model that visualises an improved regional managerial approach is shown in Fig. 3. These models do not provide a blueprint for an effective and efficient managerial approach,

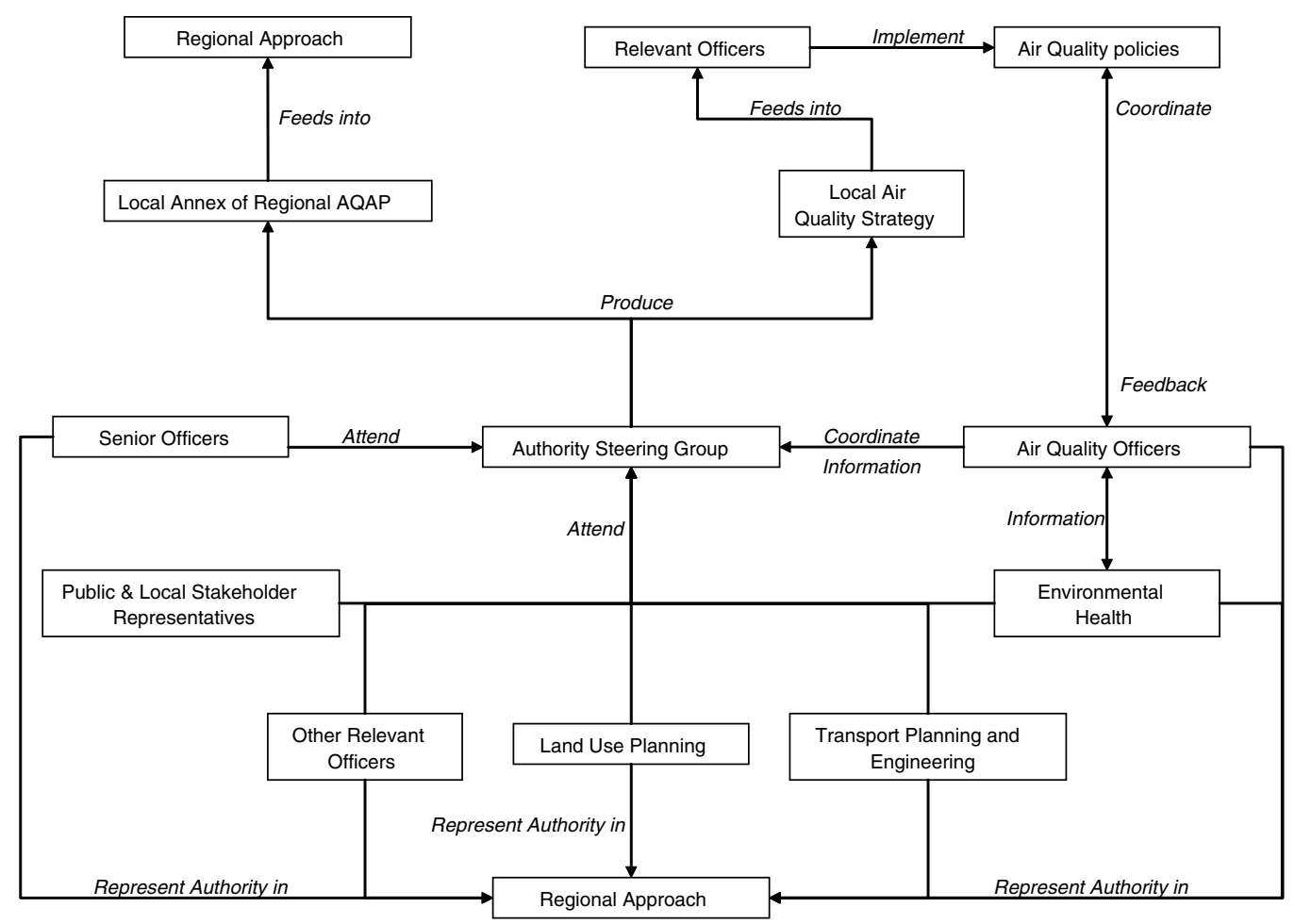

Figure 2: Conceptual model of an improved managerial approach for LAQM at the case study LA. 


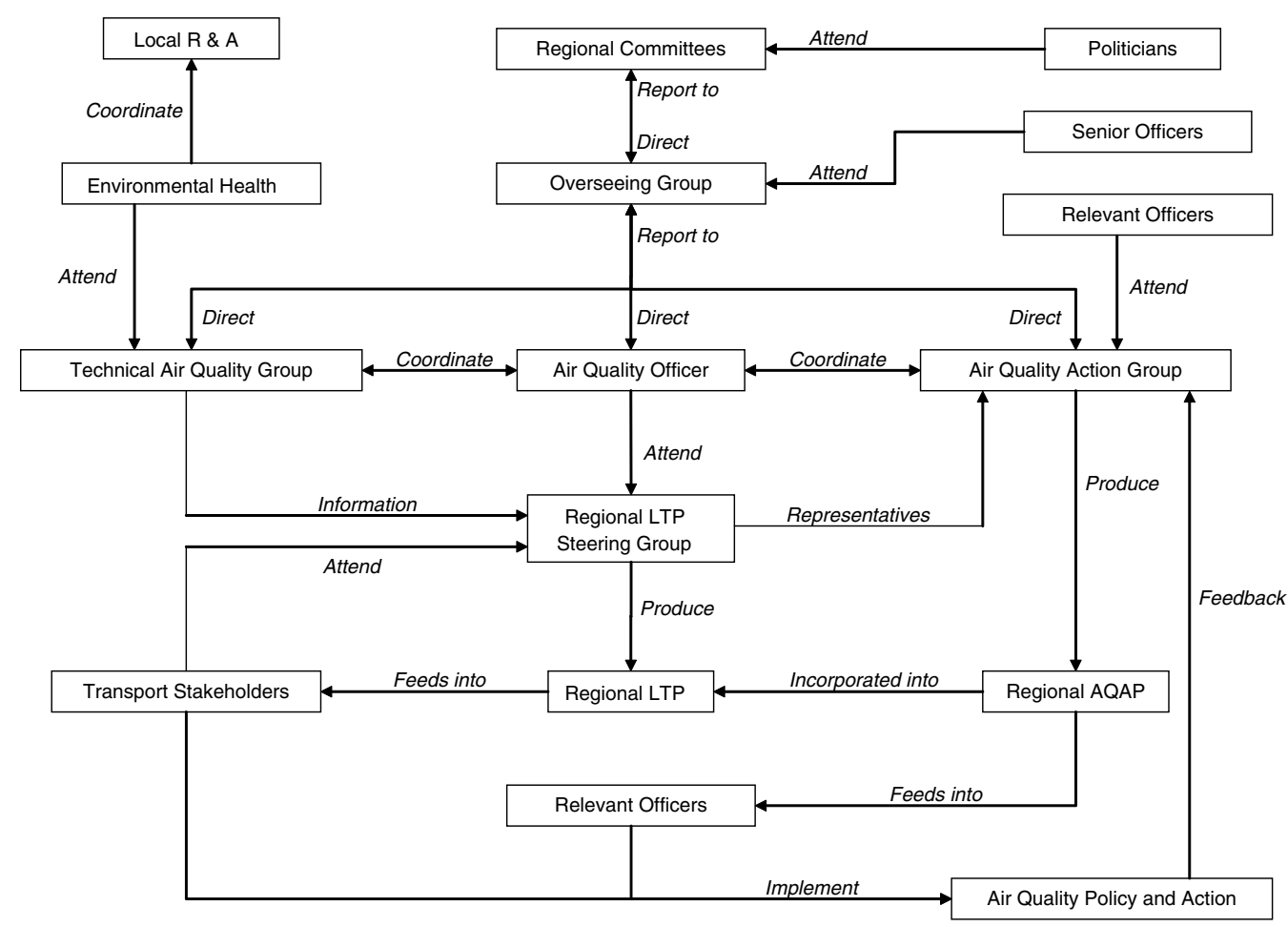

Figure 3: Conceptual model of an improved regional managerial approach for LAQM.

but instead provide an approach that would overcome some of the most significant factors currently reducing efficiency and effectiveness.

The main feature of the improved approach at the LA is the establishment of an air quality steering group and designation of an officer with sufficient resources, remit and authority to coordinate the approach effectively. Chape and Davies [42] have shown the importance of such strategic management champions, and found that individuals with the commitment and authority to introduce major changes are vital to the success of strategic approaches. The improved approach would also provide a defined mechanism into which key stakeholders can be informed, involved and offer support for air quality issues. Implementation of a managerial approach based upon these principles would bring the approach more in line with what is suggested in guidance. It would also aid improvement of senior-level understanding, leadership and direction for LAQM, and would go some way to solving the capacity and capability concerns relating to environmental health. Environmental health could continue to coordinate the technical approach to LAQM, for which they have sufficient capacity and capability, without struggling to coordinate an extensive, corporate managerial approach.

The effectiveness of the regional approach could be further improved by the establishment of an additional regional air quality group. The current group is primarily attended by environmental health professionals, whose expertise lies in the technical aspects of the process. The establishment of an additional, multi-disciplinary air quality action group, which focuses on policy development and implementation, would allow the current group to focus on technical aspects of LAQM, for which it has sufficient capacity and capability. It would also provide an opportunity for regional air 
quality policy to be integrated into other relevant disciplines and policy across the region, besides transport planning. This approach would also benefit from the designation of an officer with sufficient skills, remit and authority to coordinate the approach effectively. A further benefit would be provided by increased senior-level involvement and direction in the regional approach. This could be achieved by giving direct responsibility to a senior-level group to oversee the regional approach.

These models do not account for one of the most significant barriers identified in this study, the inappropriateness of tackling air quality problems at a local level. In developing the LAQM regime, the government felt that areas of poor air quality would be best dealt with through locally implemented measures [17]. This was brought into question by a number of environmental health and transport professionals interviewed, who felt that there is currently a lack of local solutions to the traffic-related air quality issues that are prevalent across the region. Participants felt that these solutions would be more effectively implemented at a national scale, or at the very least, require greater leadership and direction from central government on local implementation. The development of national transport-related air quality policy, supported by prescriptive guidance and resources for implementation at a local level, could provide numerous benefits to both efficiency and effectiveness in managerial aspects of LAQM. It would ensure consistency in implementation across the UK and provide greater clarity and leadership in LAQM by further defining the roles of various key stakeholders in the improvement of air quality.

\section{CONCLUSIONS}

Evidence of current UK practice in LA managerial approaches for LAQM has primarily been provided by questionnaire survey research, supplemented by a small number of case studies $[14,15,16,25]$. The findings of this case study show a large degree of consistency with this evidence. This consistency demonstrates the ability of this study to provide corroboratory evidence and thereby strengthen the evidence base in the field, and also indicates that the case study LA is a potentially representative case. The benefits of the case being representative relate to issues of external validity. A major criticism of case studies is that they offer no grounds for generalisation [43]. However, studies of highly representative cases provide a richness of evidence that makes them valuable as preliminaries to major investigations, in confirming, challenging or extending theory, and in refocusing the directions of future investigations [30]. Evidence presented in this case study is therefore also potentially significant in directing future research, and ultimately, in the development of the LAQM regime.

This study provides strong evidence to suggest that the current managerial approach for LAQM at the case study LA is both inefficient and ineffective. The fact that many of the factors contributing to this were also identified in evidence of current UK practice implies that managerial approaches for LAQM implemented by LAs across the UK are generally inefficient and ineffective. Further research is required to investigate these implications. Such investigations would provide valuable evidence to corroborate or contradict the findings of this study and also further strengthen the evidence base in the field. They may also provide evidence of the most efficient and effective managerial approaches implemented by LAs, and thus offer invaluable recommendations for achieving better practice.

Despite the lack of corroboratory evidence to many of the findings of this study, the recommendations for an improved managerial approach could be significant to authorities experiencing similar difficulties to the case. Hence, the conclusions and recommendations presented in this study should be considered by LAs and the government to aid the development of effective managerial approaches for LAQM, and with it a LAQM process that is more effective at improving air quality. 


\section{REFERENCES}

[1] Environment, Transport and Regional Affairs Committee, Local Leadership, Local Choice, Stationary Office Books: London, 1999.

[2] LGA, Local Government White Paper, Local Government Association, http://whitepaper.lga. gov.uk, 2006.

[3] Llewellyn, A. (ed.), Local Authority Directory, SAGE Publications: London, 2006.

[4] HM Government, The Local Government Act 2002, The Stationery Office: London, 2002.

[5] Chandler, J.A., Local Government Today, 3rd edn, Manchester University Press: Manchester, 2001.

[6] DCLG, Strong and Prosperous Communities: The Local Government White Paper, The Stationery Office: London, 2006.

[7] HM Government, The Environment Act 1995, Chapter 25 (Part IV), The Stationery Office: London, 1995.

[8] DoE, The United Kingdom National Air Quality Strategy, The Stationery Office: London, 1997.

[9] DETR, Scottish Executive, National Assembly for Wales \& Department of the Environment in Northern Ireland. The Air Quality Strategy for England, Scotland, Wales and Northern Ireland. Working Together for Clean Air, The Stationery Office: London, 2000.

[10] DEFRA, Scottish Executive, Welsh Assembly Government \& Department of the Environment Northern Ireland. The Air Quality Strategy for England, Scotland, Wales and Northern Ireland, The Stationery Office: London, 2007.

[11] DoE, This Common Inheritance. Britain's Environmental Strategy, Department of the Environment: London, 1990.

[12] Longhurst, J.W.S., Lindley, S.D., Watson, A.F.R. \& Conlan, D.E., The introduction of local air quality management in the United Kingdom: a review and theoretical framework. Atmospheric Environment, 30, pp. 3975-3985, 1996. doi:10.1016/1352-2310(96)00114-8

[13] Council of the European Union, Council directive 96/62/EC of 27 September 1996 on ambient air quality assessment and management. Official Journal of the European Communities, L296, pp. 53-63, 1996.

[14] Beattie, C.I., Longhurst, J.W.S. \& Woodfield, N.K., Air quality management: evolution of policy and practice in the UK as exemplified by the experience of English local government. Atmospheric Environment, 35(8), pp. 1479-1490, 2001. doi:10.1016/S1352-2310(00)00311-3

[15] Longhurst, J.W.S., Beattie, C.I., Chatterton, T.J., Hayes, E.T., Leksmono, N.S. \& Woodfield, N.K., Local air quality management as a risk management process: assessing, managing and remediating the risk of exceeding an air quality objective in Great Britain. Environment International, 32(8), pp. 934-947, 2006. doi:10.1016/j.envint.2006.06.006

[16] Beattie, C.I., Longhurst, J.W.S. \& Woodfield, N.K., Air Quality Action Plans: early indicators of urban local authority practice in England. Environmental Science \& Policy, 5(6), pp. 463-470, 2002. doi:10.1016/S1462-9011(02)00094-1

[17] DEFRA \& National Assembly for Wales, Part IV of the Environment Act 1995: Local Air Quality Management. Policy Guidance LAQM. PG(03), Department for Environment Food and Rural Affairs: London, 2003.

[18] Longhurst, J.W.S. \& Elsom, D.M., A theoretical perspective on air quality management in the UK. Air Pollution V. Modelling, Monitoring and Management, eds H. Power, T. Tirabassi \& C.A. Brebbia, Computational Mechanics Publications: Southampton, pp. 25-35, 1997.

[19] Ing, C., Beattie, C.I. \& Longhurst, J.W.S., Progress with implementing local air quality management in rural areas of England. Journal of Environmental Management, 61(2), pp. 137-147, 2001. doi:10.1006/jema.2000.0391 
[20] Elsom, D.M., Development and implementation of strategic frameworks for air quality management in the UK and European Community. Journal of Environmental Planning and Management, 42, pp. 103-121, 1999. doi:10.1080/09640569911325

[21] NSCA, The How to Guide: Consultation for Local Air Quality Management, National Society for Clean Air: Brighton, 1999.

[22] NSCA, Air Quality Action Plans: Interim Guidance for Local Authorities, National Society for Clean Air: Brighton, 2000.

[23] NSCA, Air Quality: Planning for Action, National Society for Clean Air: Brighton, 2001.

[24] Beattie, C.I. \& Longhurst, J.W.S., Local Air Quality Management: A Best Practice Guide, University of the West of England: Bristol, 1999.

[25] Beattie, C.I. \& Longhurst, J.W.S., Joint working within local government: air quality as a case-study. Local Environment, 5(4), pp. 401-414, 2000. doi:10.1080/713684890

[26] Cameron, K.S., Domains of organisational effectiveness in collages and universities. Academy of Management Journal, 24, pp. 25-47, 1981. doi:10.2307/255822

[27] Lewin, A.Y. \& Minton, J.W., Determining organisational effectiveness: another look, and an agenda for research. Management Science, 32, pp. 514-538, 1986. doi:10.1287/mnsc.32.5.514

[28] Ostroff, C. \& Schmitt, N., Configurations of organizational effectiveness and efficiency. Academy of Management Journal, 36(6), pp. 1345-1361, 1993. doi:10.2307/256814

[29] Pennings, P.S. \& Goodman, J.M., Toward a workable framework. New Perspectives on Organizational Effectiveness, eds P.S. Pennings \& J.M. Goodman, Jossey-Bass: San Fransisco, pp. 146-184, 1977.

[30] Burns, R.B., Introduction to Research Methods, 4th edn, SAGE Publications: London, 2000.

[31] Fontana, A. \& Frey, J.H., Interviewing. The Art of Science. Handbook of Qualitative Research, eds N.K. Denzin \& Y.S. Lincoln, SAGE Publications: London, pp. 361-376, 1994.

[32] Murphy, J.T., Getting the Facts: A Fieldwork Guide for Evaluators \& Policy Analysts, Goodyear Publishing: Santa Monica, 1980.

[33] Yin, R.K., Case Study Research: Design and Methods, 3rd edn, Sage: Thousand Oaks, 2003.

[34] Denzin, N.K., The Research Act: A Theoretical Introduction to Sociological Methods, 3rd edn, Prentice Hall: New Jersey, 1989.

[35] Patton, M.Q., Qualitative Research \& Evaluation Methods, 3rd edn, SAGE Publications: London, 2002.

[36] Braun, V. \& Clark, V., Using thematic analysis in psychology. Qualitative Research in Psychology, 3, pp. 77-101, 2006. doi:10.1191/1478088706qp063oa

[37] Campbell, S., Green cities, growing cities, just cities? Urban planning and the concentrations of sustainable development. Journal of the American Planning Association, 62(3), pp. 296-312, 1996. doi:10.1080/01944369608975696

[38] Tewdwr-Jones, M., Development control and the legitimacy of planning decisions. Town Planning Review, 66, pp. 163-181, 1995.

[39] Miles, M.B., Qualitative data as an attractive nuisance. Administrative Science Quarterly, 24, pp. 590-601, 1979. doi:10.2307/2392365

[40] Air Quality Consultants \& Air Quality Management Resource Centre. Evaluation of the First Round of the Local Air Quality Management Process, University of the West of England: Bristol, 2002.

[41] Longhurst, J.W.S., Beattie, C.I., Chatterton, T.J., Elsom, D.M., Leksmono, N.S. \& Woodfield, N.K., A critical evaluation of the local air quality management framework in Great 
Britain. Is it a Transferable Process? Regional and Local Aspects of Air Quality Management, eds D.M. Elsom \& J.W.S. Longhurst, WIT Press: Southampton, pp. 51-81, 2004.

[42] Chape, A. \& Davies, P., Implementing strategic management in local government: Liverpool City Council as a case study. Local Government Policy Making, 20, pp. 3-10, 1993.

[43] Gomm, R., Hammersley, M. \& Foster, P., Case Study and Generalisation. Case Study Method, eds R. Gomm, M. Hammersley \& P. Foster, SAGE Publications: London, pp. 98-116, 2000. 